\title{
Pressure effect of glass transition temperature in Zr46.8Ti8.2Cu7.5Ni10Be27.5 bulk metallic glass
}

Jiang, Jianzhong; Roseker, W.; Sikorski, M.; Cao, Q. P.; Xu, F.

\section{Published in:}

Applied Physics Letters

Link to article, DOI:

$10.1063 / 1.1675937$

Publication date:

2004

Document Version

Publisher's PDF, also known as Version of record

Link back to DTU Orbit

Citation (APA):

Jiang, J., Roseker, W., Sikorski, M., Cao, Q. P., \& Xu, F. (2004). Pressure effect of glass transition temperature in Zr46.8Ti8.2Cu7.5Ni10Be27.5 bulk metallic glass. Applied Physics Letters, 84(11), 1871-1873.

https://doi.org/10.1063/1.1675937

\section{General rights}

Copyright and moral rights for the publications made accessible in the public portal are retained by the authors and/or other copyright owners and it is a condition of accessing publications that users recognise and abide by the legal requirements associated with these rights.

- Users may download and print one copy of any publication from the public portal for the purpose of private study or research.

- You may not further distribute the material or use it for any profit-making activity or commercial gain

- You may freely distribute the URL identifying the publication in the public portal 


\title{
Pressure effect of glass transition temperature in $\mathrm{Zr}_{46.8} \mathrm{Ti}_{8.2} \mathrm{Cu}_{7.5} \mathrm{Ni}_{10} \mathrm{Be}_{27.5}$ bulk metallic glass
}

\author{
J. Z. Jiang ${ }^{\text {a) }}$ \\ Department of Materials Science and Engineering, Zhejiang University, Hangzhou, 310027, \\ People's Republic of China and Department of Physics, Building 307, Technical University of Denmark, \\ DK-2800 Lyngby, Denmark \\ W. Roseker, M. Sikorski, Q. P. Cao, and F. Xu \\ Department of Physics, Building 307, Technical University of Denmark, DK-2800 Lyngby, Denmark
}

(Received 28 October 2003; accepted 16 January 2004)

\begin{abstract}
Pressure effects on glass transition temperature and supercooled liquid region of a $\mathrm{Zr}_{46.8} \mathrm{Ti}_{8.2} \mathrm{Cu}_{7.5} \mathrm{Ni}_{10} \mathrm{Be}_{27.5}$ bulk glass have been investigated by performing in situ high-temperature and high-pressure $\mathrm{x}$-ray powder diffraction measurements using synchrotron radiation. The glass transition was detected from the change of the slope of peak position as a function of temperature. It is found that the glass transition temperature increases with pressure by $4.4 \mathrm{~K} / \mathrm{GPa}$ for the $\mathrm{Zr}_{46.8} \mathrm{Ti}_{8.2} \mathrm{Cu}_{7.5} \mathrm{Ni}_{10} \mathrm{Be}_{27.5}$ bulk glass, and the supercooled liquid range decreases with pressure by $2.9 \mathrm{~K} / \mathrm{GPa}$ in a pressure range of $0-2.2 \mathrm{GPa}$. This method opens a possibility to study the pressure effect of glass transition process in glassy systems under high pressures ( $>1 \mathrm{GPa}$ ). (C) 2004 American Institute of Physics. [DOI: 10.1063/1.1675937]
\end{abstract}

Understanding the glass transition in a variety of glassy systems such as polymers, silica, orientational glasses, spin glasses, and metallic glasses is still a major scientific challenge. ${ }^{1}$ The pressure dependence of the glass transition temperature, $T_{g}$, is one of the key issues regarding the validity of existing various theories and establishing new theories. ${ }^{2}$ Using free volume theory, it has been predicted that the glass transition temperature will increase and then level off with increasing pressure. ${ }^{3}$ So far, most experimental results have been reported for pressures below $1 \mathrm{GPa}$ and indicate that the glass transition temperature increases with pressure. ${ }^{2}$ For metallic systems, rare experimental data of $T_{g}$ vs pressure have been reported. Samwer et al. ${ }^{4}$ reported an increase of $T_{g}$ with pressure of $3.6 \mathrm{~K} / \mathrm{GPa}$ for a $\mathrm{Zr}_{46.8} \mathrm{Ti}_{8.2} \mathrm{Cu}_{7.5} \mathrm{Ni}_{10} \mathrm{Be}_{27.5}$ bulk metallic glass by an indirect enthalpy recovery method, ${ }^{5}$ in which ambient-pressure differential scanning calorimetry (DSC) measurements of samples annealed under pressure were carried out. In this letter, we report a direct method, based on in situ hightemperature and high-pressure x-ray powder diffraction (XRD) measurements using synchrotron radiation, for studying the glass transition temperature under high pressure (above $1 \mathrm{GPa}$ ). For comparison, we also study the $\mathrm{Zr}_{46.8} \mathrm{Ti}_{8.2} \mathrm{Cu}_{7.5} \mathrm{Ni}_{10} \mathrm{Be}_{27.5}$ bulk metallic glass, one of the most widely studied bulk metallic glasses. ${ }^{6}$ We found that the glass transition temperature increases with pressure by 4.4 $\mathrm{K} / \mathrm{GPa}$, in good agreement with the data reported in Ref. 4, and the supercooled liquid range decreases with pressure by $2.9 \mathrm{~K} / \mathrm{GPa}$ in a pressure range of $0-2.2 \mathrm{GPa}$. The method could be applied to other glassy systems.

Ingots of the $\mathrm{Zr}_{46.8} \mathrm{Ti}_{8.2} \mathrm{Cu}_{7.5} \mathrm{Ni}_{10} \mathrm{Be}_{27.5}$ bulk glass were produced by alloying the pure components by induction melting in a levitation device under purified Ar atmosphere

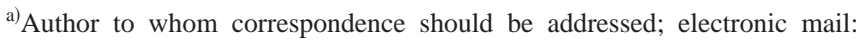
jiang@fysik.dtu.dk or jiangjz@zju.edu.cn
}

and quenching by contact with water-cooled copper surface. This material was remelted in a fused silica crucible and die-cast into a copper mold, to obtain 60-mm-long rods with a diameter of $5 \mathrm{~mm}$. The average cooling rate was estimated to be $>20 \mathrm{~K} / \mathrm{s}$. Samples from both ends of the rods were mechanically polished and analyzed by optical microscopy and scanning electron microscopy to ascertain the absence of undesirable primary crystals, which cannot be detected by XRD below a volume fraction of about 3\%. The glass transition temperature of the glass at ambient pressure was estimated by a Perkin-Elmers Pyris Diamond DSC at a heating rate of $4 \mathrm{~K} / \mathrm{min}$ under a flow of purified argon to be $T_{g}$ $=330^{\circ} \mathrm{C}$.

In situ high-temperature and high-pressure $\mathrm{x}$-ray powder diffraction patterns for the $\mathrm{Zr}_{46.8} \mathrm{Ti}_{8.2} \mathrm{Cu}_{7.5} \mathrm{Ni}_{10} \mathrm{Be}_{27.5}$ bulk glass were recorded, using synchrotron radiation and the white-beam energy-dispersive method, as shown in Fig. 1 at a pressure of $0.84 \mathrm{GPa}$. High temperatures (up to $1500^{\circ} \mathrm{C}$ ) and high pressures (up to $8 \mathrm{GPa}$ ) could be obtained in the multi-anvil device MAX80 of HASYLAB in Hamburg, Germany. ${ }^{7}$ Similar pressures (higher than $1 \mathrm{GPa}$ ) can be accessed in many laboratories. The central part of the sample chamber consists of a cylindrical boron nitride container with an internal diameter of $1 \mathrm{~mm}$ (Fig. 2). The upper half of the container is filled with the sample, and the lower half with $\mathrm{NaCl}$ powder for pressure calibration purposes. ${ }^{8}$ Electric current is sent through a graphite heater via two appropriate anvils. The cubic chamber is compressed by six tungsten carbide anvils in a large hydraulic press. The temperature is measured by means of thermocouple voltage with a stability of $\pm 1 \mathrm{~K}$. Each run consists of a roomtemperature compression followed by an isobaric heating to high temperature in steps of 3 and $5 \mathrm{~K}$ with a recorded XRD pattern for every $10 \mathrm{~min}$. Pure $\mathrm{Zr}, \mathrm{Fe}$, and the bulk metallic glass powders were used to examine the possible oxidation of samples during the heat treatments using the sample as- 


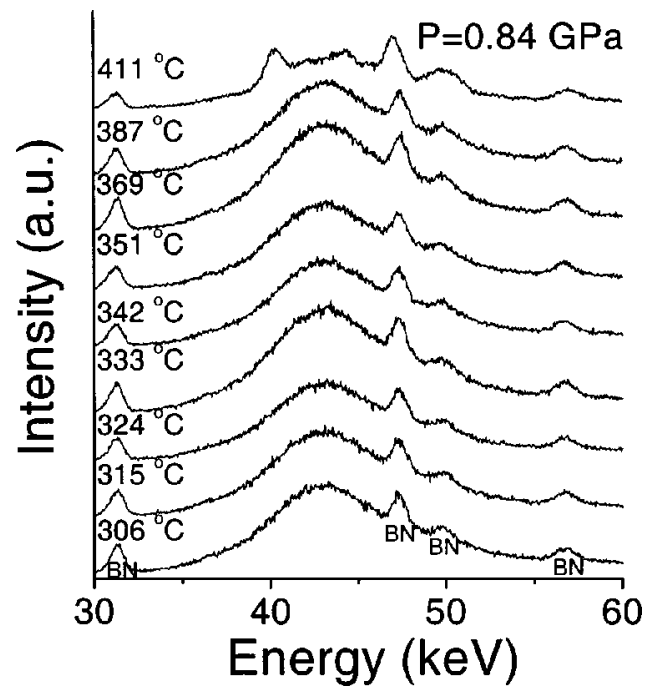

FIG. 1. In situ energy-dispersive x-ray powder diffraction patterns recorded for the $\mathrm{Zr}_{46.8} \mathrm{Ti}_{8.2} \mathrm{Cu}_{7.5} \mathrm{Ni}_{10} \mathrm{Be}_{27.5}$ bulk glass at $0.84 \mathrm{GPa}\left(E_{d}\right.$ $=101.59 \mathrm{keV} \AA$ ) with an exposure time of $10 \mathrm{~min}$ for a given temperature. Steps of $5^{\circ}$ and $3^{\circ}$ were used for the temperature ranges of $250-300$ and $300-420^{\circ} \mathrm{C}$, respectively. The broad amorphous peak, located at about 43 $\mathrm{keV}$, and a few Bragg peaks from BN are detected.

sembly. It was found that only pure metallic phases in the three systems were detected after heat treatments at temperatures up to $550{ }^{\circ} \mathrm{C}$. In addition, we have also carried out room-temperature compression XRD measurements up to about $50 \mathrm{GPa}$ using a diamond-anvil cell. A pressure transmitting medium of 4:1 methanol:ethanol solution was used. The actual pressure was calculated from the wavelength shift of the ruby line using the nonlinear pressure scale of Mao et $a .^{9}$

The peak position of the broad amorphous peak of the $\mathrm{Zr}_{46.8} \mathrm{Ti}_{8.2} \mathrm{Cu}_{7.5} \mathrm{Ni}_{10} \mathrm{Be}_{27.5}$ bulk glass, estimated from the fit using a Gaussian line profile, as a function of temperature, is shown in Fig. 3. The slope of peak position versus temperature is clearly altered when the sample temperature rises from the glassy state to the supercooled liquid state. It is well known that at around glass transition temperature the slope of thermal expansion of glasses changes. For metallic glasses, most likely having a dense random packed structure,

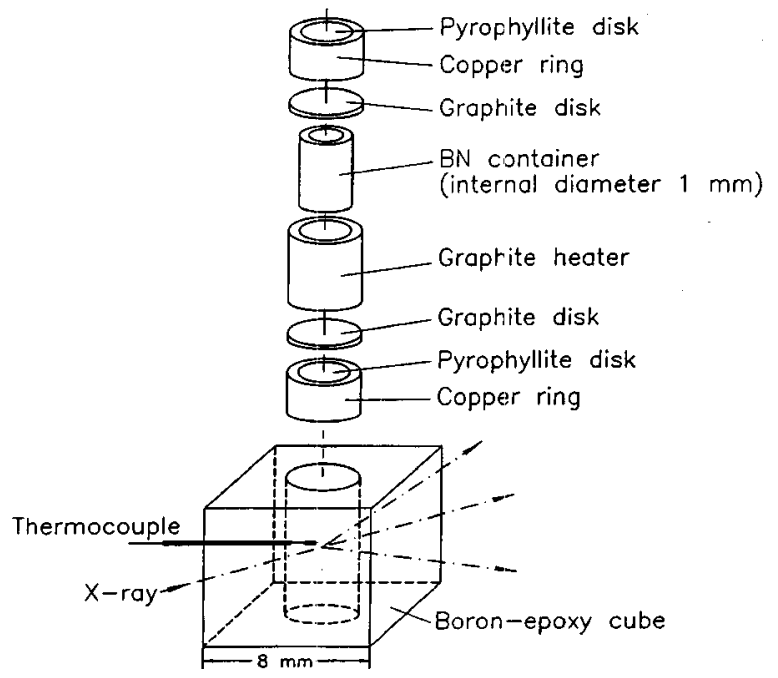

FIG. 2. The sample chamber for high-pressure and high-temperature x-ray

powder diffraction studies.
Downloaded 03 Apr 2010 to 192.38 .67 .112 . Redistribution subject to AIP license or copyright; see http://apl.aip

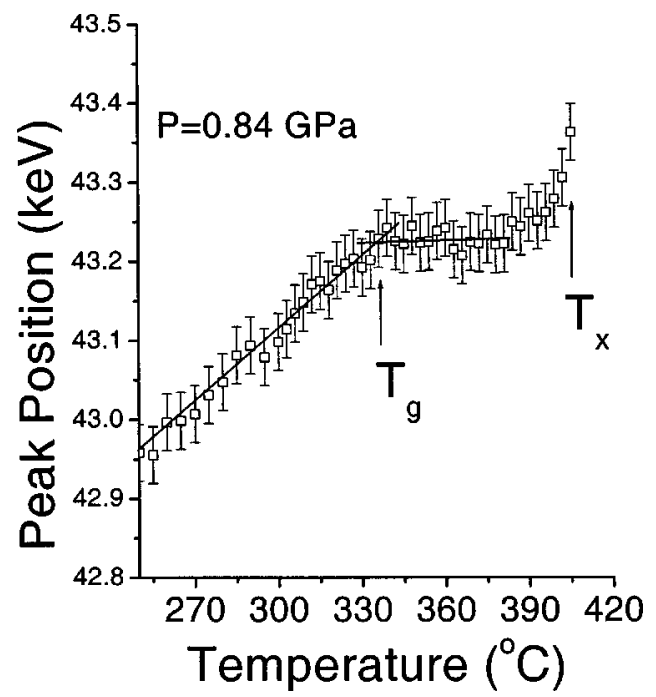

FIG. 3. The peak position of the broad amorphous peak for the $\mathrm{Zr}_{46.8} \mathrm{Ti}_{8.2} \mathrm{Cu}_{7.5} \mathrm{Ni}_{10} \mathrm{Be}_{27.5}$ bulk glass, estimated from the fit using a Gaussian line profile, as a function of temperature. The glass transition temperature was estimated by the interpolation technique shown.

the maximum position $\left(1 / d_{\max }\right.$ in $\left.\AA^{-1}\right)$ in an $\mathrm{x}$-ray powder diffraction pattern is proportional to $1 / D$, where $D$ is the average nearest neighbor distance in the metallic glass deduced from the position of the first peak in the radial distribution function curve (in $\AA$ ). ${ }^{10}$ Thus, the peak position versus temperature, as shown in Fig. 3, might link to the relationship of the average nearest neighbor distance versus temperature in the metallic glass. To support this argument, we further estimate bulk modulus of a similar bulk glass, $\mathrm{Zr}_{41.2} \mathrm{Ti}_{13.8} \mathrm{Cu}_{12.5} \mathrm{Ni}_{10} \mathrm{Be}_{22.5}$, from high-pressure (up to 50 $\mathrm{GPa}$ XRD measurements. Figure 4 shows compression data, $\left[d_{\max }(P) / d_{\max }(0)\right]^{3}$ versus pressure, of the bulk glass together with a solid fitting curve obtained from the Birch equation of state. ${ }^{11}$ The zero-pressure bulk modulus of the glass is found to be $107 \pm 10 \mathrm{GPa}$, which is in good agreement with 112 GPa for the alloy estimated by a resonant ultrasound spectroscopy. ${ }^{12}$ This result strongly indicates that $\left[d_{\max }(P) / d_{\max }(0)\right]^{3}$ is proportional to the ratio of the volume of the glass at a given pressure to that at zero pressure, $V(P) / V(0)$, of the metallic glass. Therefore, the glass transition temperature for the $\mathrm{Zr}_{46.8} \mathrm{Ti}_{8.2} \mathrm{Cu}_{7.5} \mathrm{Ni}_{10} \mathrm{Be}_{27.5}$ bulk glass under pressure can be estimated by an interpolation

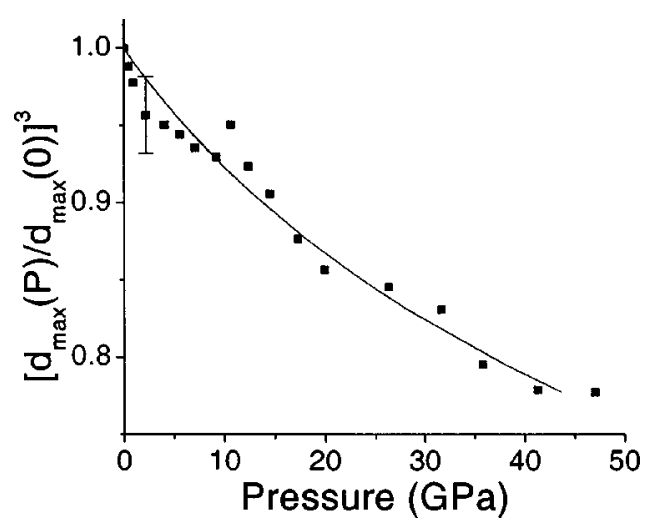

FIG. 4. Compression data, $\left[d_{\max }(P) / d_{\max }(0)\right]^{3}$ vs pressure, of a $\mathrm{Zr}_{41.2} \mathrm{Ti}_{13.8} \mathrm{Cu}_{12.5} \mathrm{Ni}_{10} \mathrm{Be}_{22.5}$ bulk glass at room temperature. The solid curve is calculated from the Birch equation of state. 


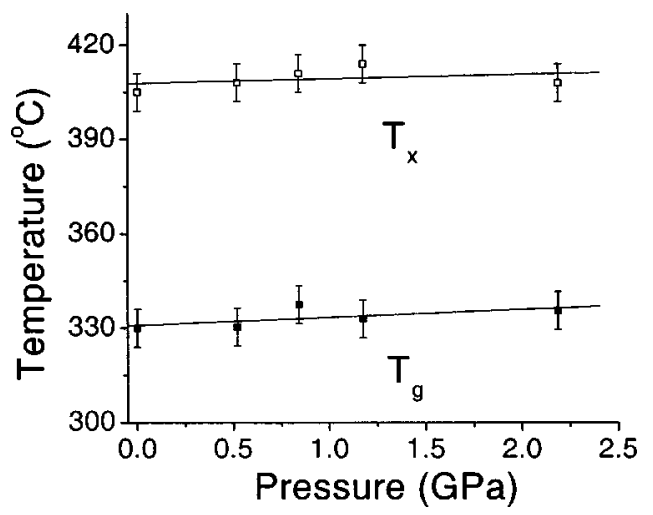

FIG. 5. The glass transition and crystallization temperature of the $\mathrm{Zr}_{46.8} \mathrm{Ti}_{8.2} \mathrm{Cu}_{7.5} \mathrm{Ni}_{10} \mathrm{Be}_{27.5}$ bulk glass as a function of pressure. The data were linearly fitted as solid lines.

technique as shown in Fig. 3. Pressure dependencies of the glass transition temperature and crystallization temperature using a heating rate of about $0.3 \mathrm{~K} / \mathrm{min}$ for the $\mathrm{Zr}_{46.8} \mathrm{Ti}_{8.2} \mathrm{Cu}_{7.5} \mathrm{Ni}_{10} \mathrm{Be}_{27.5}$ bulk glass are depicted in Fig. 5 . The value of the glass transition temperature at ambient pressure estimated here is similar to the value estimated by DSC although the heating rate differs. It reveals that the glass transition temperature increases with pressure by about 4.4 $\mathrm{K} / \mathrm{GPa}$ for the metallic glass, which is in good agreement with the reported data of $3.6 \mathrm{~K} / \mathrm{GPa}$ estimated from ex situ measurements of enthalpy change for the glass annealed under pressure. ${ }^{4}$ The value compares well with known data of the shift of $T_{g}$ with pressure in other glass-forming systems. ${ }^{2}$ We further found that the supercooled liquid region, defined by the crystallization temperature, $T_{x}$, minus the glass transition temperature, $T_{g}$, decreases with pressure by about 2.9 $\mathrm{K} / \mathrm{GPa}$. The pressure-dependence of the supercooled liquid region has been measured for metallic glassy systems. The slope of $T_{x}$ versus pressure, $1.5 \mathrm{~K} / \mathrm{GPa}$, for a heating rate of $0.3 \mathrm{~K} / \mathrm{min}$ used here is in good agreement with the reported data, $1.7 \mathrm{~K} / \mathrm{GPa}$, for a heating rate of about $3 \mathrm{~K} / \mathrm{min}$ for the same glass, although the absolute crystallization temperature shifts due to different heating rates. ${ }^{13}$
In conclusion, a technique, based on in situ hightemperature and high-pressure $\mathrm{x}$-ray powder diffraction measurements using synchrotron radiation, was developed for studying the glass transition temperature under pressures above $1 \mathrm{GPa}$. The method can be applied to other glassy systems with glass transition temperatures higher than ambient temperature. We believe that more experimental data for pressure dependencies of the glass transition and supercooled liquid region in the pressure range above $1 \mathrm{GPa}$ in a variety of glassy systems will be available. The results will no doubt further deepen our understanding of the glass transition, one of the most fascinating open questions in materials science and condensed-matter physics.

The authors thank HASYLAB in Hamburg, MAX-lab in Lund, ESRF in Grenoble, and Spring8 in Japan for use of the synchrotron radiation facilities. Financial support from the National Natural Science Foundation of China (No. 50341032), Zhejiang University, the Danish Technical Research Council, and the Danish Natural Sciences Research Council is gratefully acknowledged.

${ }^{1}$ P. G. Debenedetti and F. H. Stillinger, Nature (London) 410, 259 (2001).

${ }^{2}$ P. G. Debenedetti, Metastable Liquid (Princeton University Press, Princeton, NJ, 1996), p. 253.

${ }^{3}$ I. C. Sanchez, J. Appl. Phys. 45, 4204 (1974).

${ }^{4}$ K. Samwer, R. Bush, and W. L. Johnson, Phys. Rev. Lett. 82, 580 (1999).

${ }^{5}$ G. Ruitenberg, P. de Hey, F. Sommer, and J. Sietsma, Phys. Rev. Lett. 79, 4830 (1997)

${ }^{6}$ X. P. Tang, U. Geyer, R. Bush, W. L. Johnson, and Y. Wu, Nature (London) 402, 160 (1999).

${ }^{7}$ J. Z. Jiang, J. S. Olsen, L. Gerward, S. Abdali, J. Eckert, N. Schlorke-de Boer, L. Schultz, J. Truckenbrodt, and P. X. Shi, J. Appl. Phys. 87, 2664 (2000).

${ }^{8}$ D. L. Decker, J. Appl. Phys. 42, 3239 (1971).

${ }^{9}$ H. K. Mao, P. M. Bell, J. W. Shaner, and D. J. Steinberg, J. Appl. Phys. 49, 3276 (1978).

${ }^{10}$ A. Tomizuka, H. Iwasaki, K. Fukamichi, and T. Kikegawa, J. Phys. F: Met. Phys. 14, 1507 (1984).

${ }^{11}$ F. Birch, J. Appl. Phys. 9, 279 (1938); Phys. Rev. 71, 809 (1947).

${ }^{12}$ Y. He, R. B. Schwarz, D. Mandrus, and L. Jacobson, J. Non-Cryst. Solids 205, 602 (1996)

${ }^{13}$ J. Z. Jiang, L. Gerward, and Y. S. Xu, Appl. Phys. Lett. 81, 4347 (2002). 